\title{
Radiation Pneumonitis Changes over Time after Stereotactic Body Radiation Therapy for Lung Tumors: Post-treatment Cavity (Sunny-side-up Egg-like) Changes
}

\author{
TOSHIYA MAEBAYASHI ${ }^{1}$, NAOYA ISHIBASHI ${ }^{1}$, TAKUYA AIZAWA ${ }^{1}$, \\ MASAKUNI SAKAGUCHI ${ }^{1}$, TSUTOMU SATO ${ }^{2}$, JIRO KAWAMORI ${ }^{3}$ and YOSHIAKI TANAKA ${ }^{4}$ \\ ${ }^{1}$ Department of Radiology, Nihon University School of Medicine, Tokyo, Japan; \\ ${ }^{2}$ Radiology Clinic, Sonoda Medical Corporation, Tokyo, Japan; \\ ${ }^{3}$ Department of Radiation Oncology, St. Luke's International Hospital, Tokyo, Japan; \\ ${ }^{4}$ Department of Radiation Oncology, Kawasaki Saiwai Hospital, Kawasaki, Japan
}

\begin{abstract}
Background: Stereotactic body radiation therapy (SBRT) is a viable treatment option for stage I non-small cell lung carcinoma (NSCLC) in non-surgical candidates. Although treatment with a 100 Gy biological effective dose is considered to carry a low risk of local recurrence, only a few reports have focused on changes in tumors or surrounding intact portions of the lung after SBRT. Such changes are assessed using diagnostic imaging specifically for radiation pneumonitis, which can be difficult to distinguish from local tumor recurrence. Cavity changes after SBRT observed around the tumor within the irradiated field resemble an egg, fried with the yolk facing upward, and are thus referred to as 'sunny-side-up egg-like' changes. They have the appearance of a residual tumor in the center. This study aimed to evaluate patients with post-treatment cavity changes after SBRT for stage I NSCLC. Patients and Methods: Cavity changes were observed in four cases. Tumors were irradiated with a 6-MV X-ray using 10 fixed ports. The single dose was $12 \mathrm{~Gy}$, the total dose $48 \mathrm{~Gy}$. Results: The time until the appearance of cavity changes ranged from 4 to 9 months (median=6 months). The cavity changes disappeared in 12-20 months (median=16 months). Conclusion: Cavity changes (sunny-side-up egg-like) in the lungs may develop after SBRT for stage I NSCLC.
\end{abstract}

Correspondence to: Toshiya Maebayashi, MD, Ph.D., Department of Radiology, Nihon University School of Medicine, 30-1 Oyaguchi Kami-cho, Itabashi-ku, Tokyo, 173-8610, Japan. Tel: +81 339728111 (ext. 8328), Fax: +81 339582454, e-mail: maebayashi.toshiya@nihonu.ac.jp

Key Words: Radiation pneumonitis, stereotactic body radiation therapy, cavity changes, non-small cell lung cancer, radiation therapy, lung cancer.
According to the Lung Cancer Management Guidelines 2014 (Japan Lung Cancer Society) (1), patients who are unable to undergo surgery for medical reasons may still be candidates for stereotactic body radiation therapy (SBRT) with radical intent. The Japan Clinical Oncology Group Study JCOG0403 protocol reportedly achieves a local control rate of $87.3 \%$ in the inoperable population and $85.4 \%$ in the operable population (2). Onishi et al. reported the local control rate to be $86 \%$ when irradiation was applied at a biologically effective dose (BED) of more than 100 Gy (3). Based on these results, in Japan, SBRT has become a standard therapy for non-small cell lung carcinoma (NSCLC) for which standard surgery is not applicable. Although treatment with a BED of $100 \mathrm{~Gy}$ is reportedly associated with a low risk of local recurrence, few studies have examined changes in tumors or surrounding intact portions of the lung after SBRT $(6,15,16)$, as assessed by diagnostic imaging focusing specifically on radiation pneumonitis, which can be difficult to distinguish from local tumor recurrence.

Cavity changes after SBRT observed around the tumor within the irradiated field resemble an egg, fried with the yolk facing upward, and are thus referred to as 'sunny-sideup egg-like' change. To our knowledge, there are no prior reports of cases with cavity changes similar to those we have recently observed after SBRT. Although the number of cases we report here is small, we continue to monitor these cases closely after the disappearance of cavity changes.

\section{Patients and Methods}

Radiotherapy. The prescribed dose was $48 \mathrm{~Gy}$ at the isocenter in four fractions over 4 days. Radiotherapy was administered using a 6-MV X-ray Siemens Primus KD2 (Siemens Oncology Care Systems, Concord, CA, USA) and performed with 10 fixed ports. For the treatment planning, the Xio (version 4.4.0-4.6.0; Elekta CMS Software, St. Louis, MO, USA) was used, and calculations 
were performed employing the Clarkson method, with reference to the superposition technique. This point was set to assure that the 95\% isodose line would satisfy the planning target volume (PTV).

When the irradiation field was set, the lesion imaged at the clinical target volume (CTV) with a long scan time was used. The CTV was defined as the visible gross tumor volume. Sites differing from the lung field in terms of clinical target number were contoured with the following parameters: a window width of 2000 and window level of -700 . The PTV was added to create a 5- to 8$\mathrm{mm}$ set-up margin. However, for cases in which the movement exceeded $2 \mathrm{~cm}$ as seen on radiographic fluoroscopy, a respirationgated system (AZ-773V, Anzai Medical, Tokyo, Japan) or an Abches (Apex Medical, Tokyo, Japan) was used.

During the period from 2004 to 2011, 32 patients underwent SBRT for stage IA NSCLC cases. However, cavity (sunny-side-up egg-like) changes were observed in only four cases $(4 / 32,12.5 \%)$, described below. The time until the appearance of cavity changes ranged from 4 to 9 months (median $=6$ months). The cavity changes disappeared in 12-20months (median=16 months).

\section{Case Report 1}

A 78-year-old man was found to have a mass in the right upper lung lobe at a medical checkup (Figure 1A). His past medical history was significant for hypertension and pneumothorax. He had smoked for more than 40 years. Transbronchial lung biopsy was performed and a biopsy sample was obtained from the right upper lobe. He was diagnosed with a stage IA squamous cell lung carcinoma and received SBRT (Figure 1E and F). Tumor decreased in size at 3 months after SBRT (Figure 1B). Cavity (sunny-side-up egg-like) changes after SBRT were seen at 7 months (Figure 1C). The time until disappearance of these cavity changes was 16 months (Figure 1D). Positron-emission tomography (PET) scan performed 16 months following SBRT showed no recurrence (Figure $1 \mathrm{G}$ ). To date, there has been no evidence of recurrence or metastasis in the 7 years after SBRT.

\section{Case Report 2}

A 75-year-old man had been followed-up by another department of our hospital and was found to have a cavity mass in the right lower lung lobe in routine follow-up (Figure 2A). The patient's medical history included laryngeal cancer (stage IIA) in 1995 and esophageal cancer (stage II) in 2003 and he had received chemoradiotherapy with a favorable response. He had smoked for more than 40 years. Transbronchial lung biopsy was performed and a biopsy sample was obtained from the right lower lobe. He was diagnosed with a stage IA squamous cell carcinoma and received SBRT (Figure $2 \mathrm{G}$ and $\mathrm{H}$ ). Tumor decreased in size at 1 month after SBRT (Figure 2B). As the tumor shrank after SBRT, the cavity within the lesion expanded. At 4 months after irradiation, more cavities had formed around the initial cavity lesion (Figure $2 \mathrm{C}$ ). The cavity within the lesion disappeared 6 months after irradiation (Figure 2D), and the surrounding cavities had also disappeared by 12 months (Figure 2E and F). There had been no evidence of local recurrence after SBRT, but he died due to the recurrence of another cancer at 3 years.

\section{Case Report 3}

A 73-year-old man was found to have a mass in the left lower lung lobe field at a medical checkup (Figure 3A). He had no medical history. He had smoked for more than 30 years. Transbronchial lung biopsy was performed and a biopsy sample was obtained from the left lower lobe. He was diagnosed with a stage IA non-small cell carcinoma and received SBRT (Figure 3E and F). Tumor decreased in size at 1 month after SBRT (Figure 3B). Cavity (sunny-side-up egg-like) changes after SBRT were seen at 9 months (Figure 3C). The time until disappearance of these cavity changes was 12 months (Figure 3D). To date, there has been no evidence of recurrence or metastasis in the 8 years after SBRT.

\section{Case Report 4}

A 85-year-old woman was found to have a mass in the right upper lung lobe at a medical checkup (Figure 4A). Her past medical history was significant hypertension and psoriasis vulgaris. She had smoked for more than 40 years. The diagnosis was based solely on PET and was stage IA. The patient received SBRT. Cavity (sunny-side-up egg-like) changes after SBRT were seen at 5 months (Figure $4 \mathrm{~B}$ and C). The time until disappearance of these cavity changes was 20 months (Figure 4D). To date, there has been no evidence of recurrence or metastasis in the 5 years since initiation of this treatment.

\section{Discussion}

Among the reports from Japan, that by Nagata et al. documented local recurrence rates at 3 years for the inoperable and operable populations of $12.7 \%$ and $14.6 \%$, respectively (2). Another study found local recurrence to essentially be absent, with the local control rate being $98 \%$ after treatment with the Radiation Therapy Oncology Group 0236 protocol (60 Gy in 3 fractions at the PTV for the periphery) (4). According to past reports, local recurrence rates ranged from $0 \%$ to $23.4 \%$, generally being about $10 \%$ (5). Thus, physicians should bear in mind the possibility of local recurrence when applying stereotactic radiotherapy in clinical settings.

To date, however, there have been few reports describing changes after SBRT as assessed by diagnostic imaging (6). 

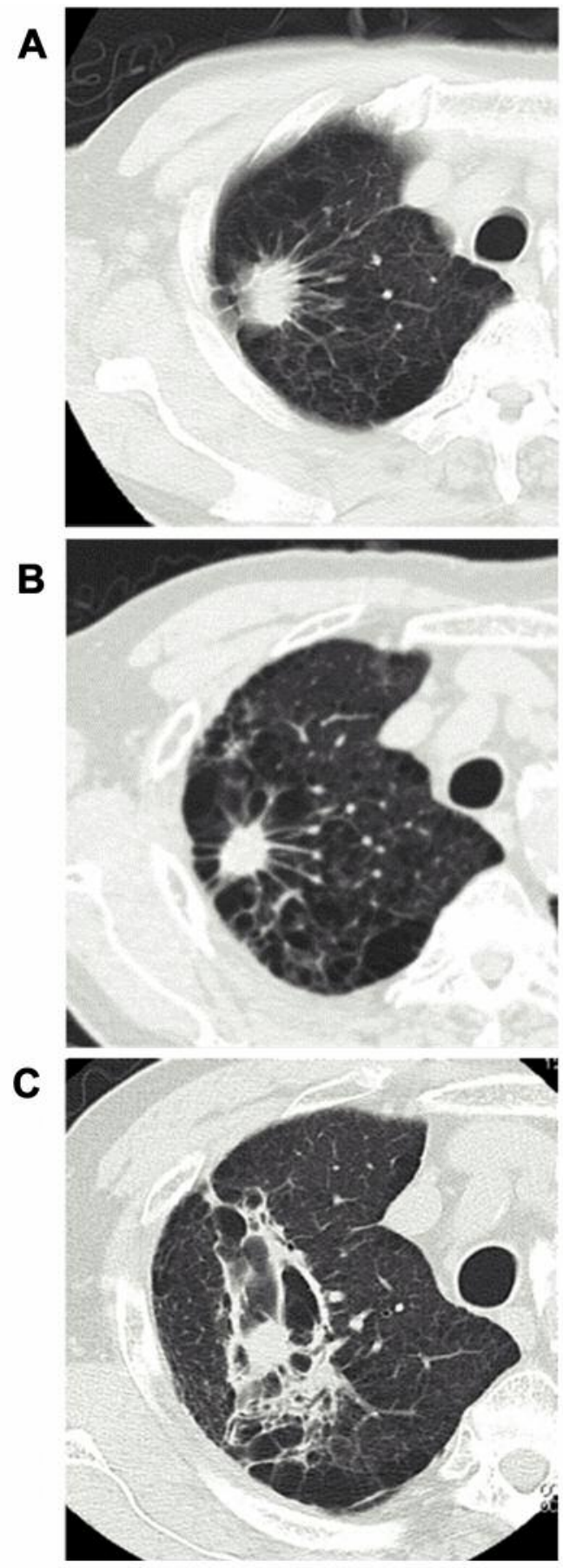

Figure 1. Computed tomographic images obtained before $(A)$ and $3(B), 7$ $(C)$, and $16(D)$ months after completion of stereotactic body radiotherapy (SBRT) for lung cancer in a 78-year-old man with squamous cell carcinoma in the right upper lobe. Cavity (sunny-side-up egg-like) changes after SBRT were seen at 7 months. The time until disappearance of these cavity changes was 16 months. E and F: SBRT image with isodose lines. The purple line is the $95 \%$ isodose curve and corresponds to the planning target volume (PTV), as determined by the Clarkson method (E). The pink line is the $80 \%$ isodose curve and corresponds to the PTV, obtained by employing the superposition technique $(F)$. A positron-emission tomography scan performed 16 months after SBRT showed no recurrence $(G)$.
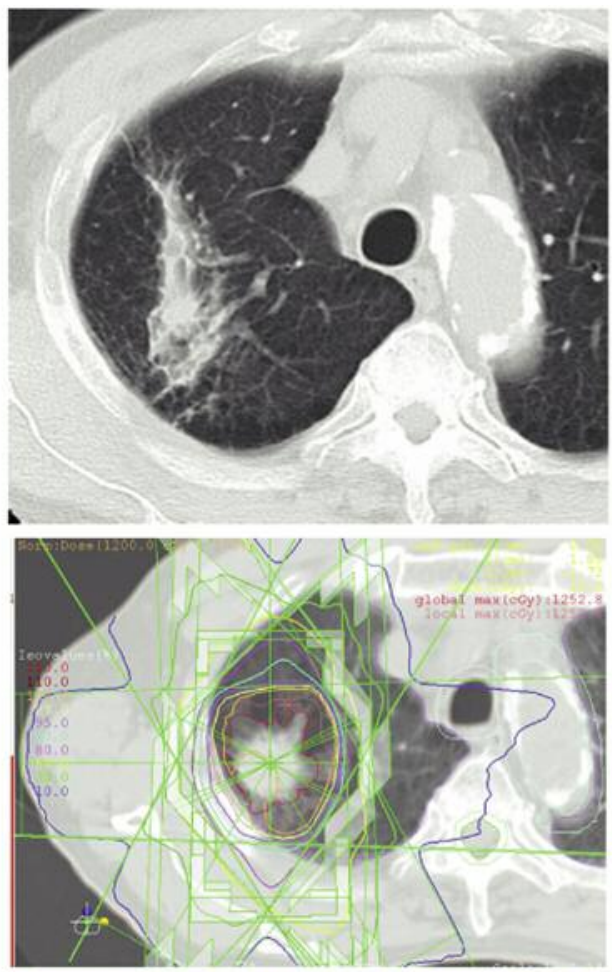

E

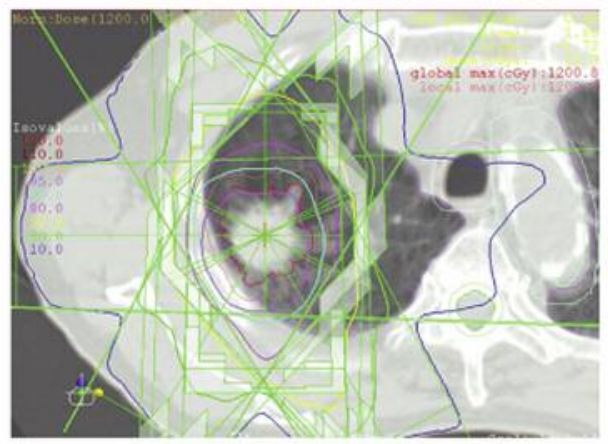

$\mathbf{F}$

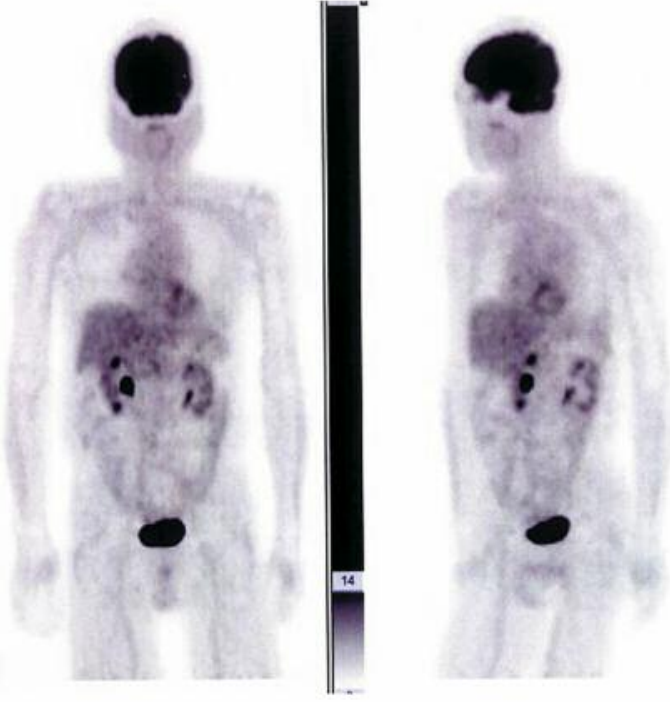




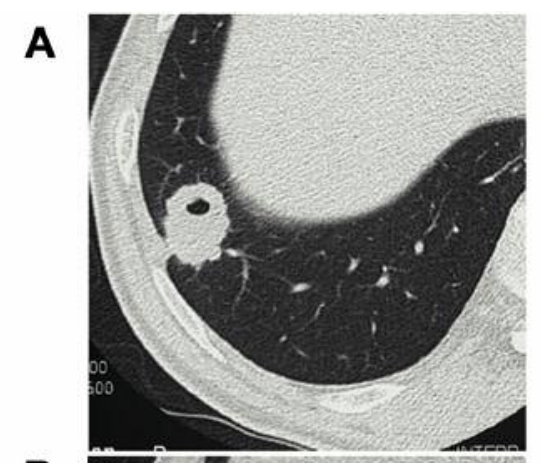

B
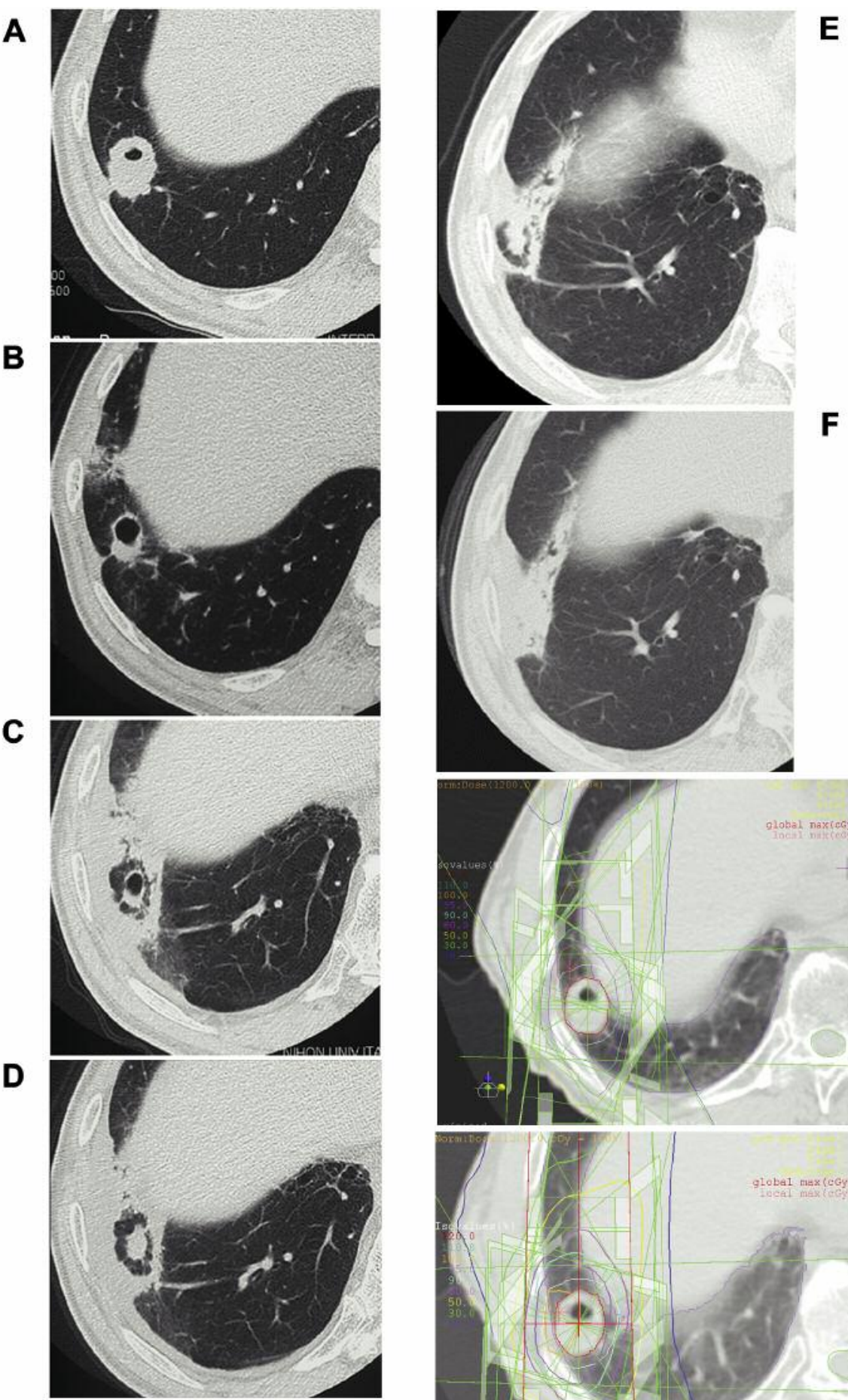

$\mathbf{F}$

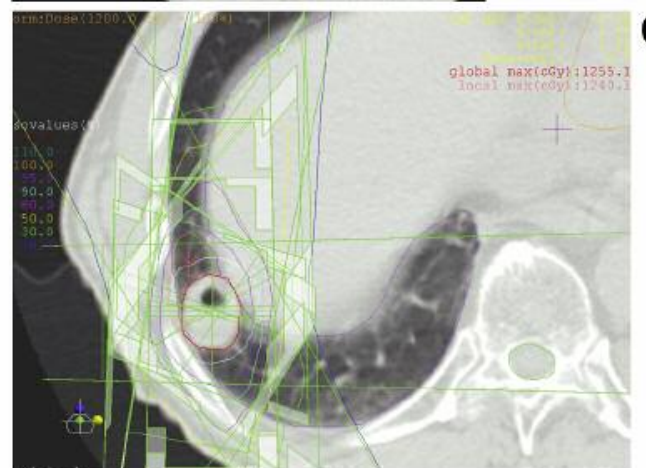

G

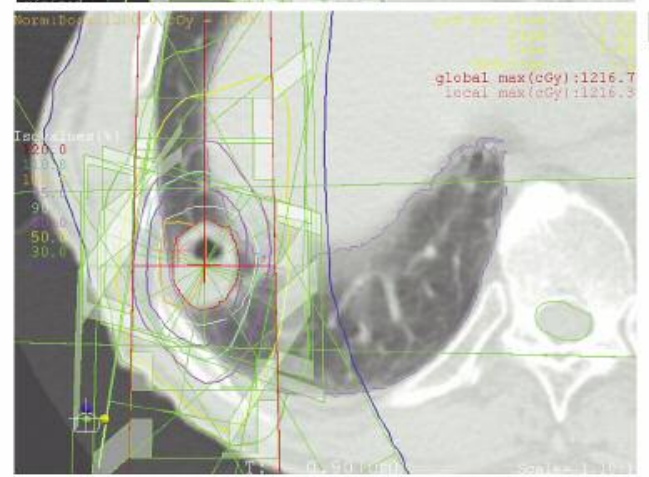

H

Figure 2. Computed tomographic images obtained before $(A)$ and $1(B), 4(C), 6(D), 12(E)$ and 17 months $(F)$ after completion of stereotactic body radiotherapy (SBRT) for lung cancer in a 75-year-old man with non-small cell carcinoma in the right lower lobe. At 4 months after irradiation, additional cavities had formed around the initial cavity lesion. The cavity inside the lesion had disappeared at 6 months (D) after irradiation, and the surrounding cavities were also gone by 12 months $(E)$. The time until disappearance of cavity changes was 17 months $(F)$. G and H: SBRT image with isodose lines. The blue line is the $90 \%$ isodose curve and corresponds to the planning target volume (PTV), as determined by the Clarkson method $(G)$. The pink line is the $80 \%$ isodose curve and corresponds to the PTV, obtained by employing the superposition technique (H). 

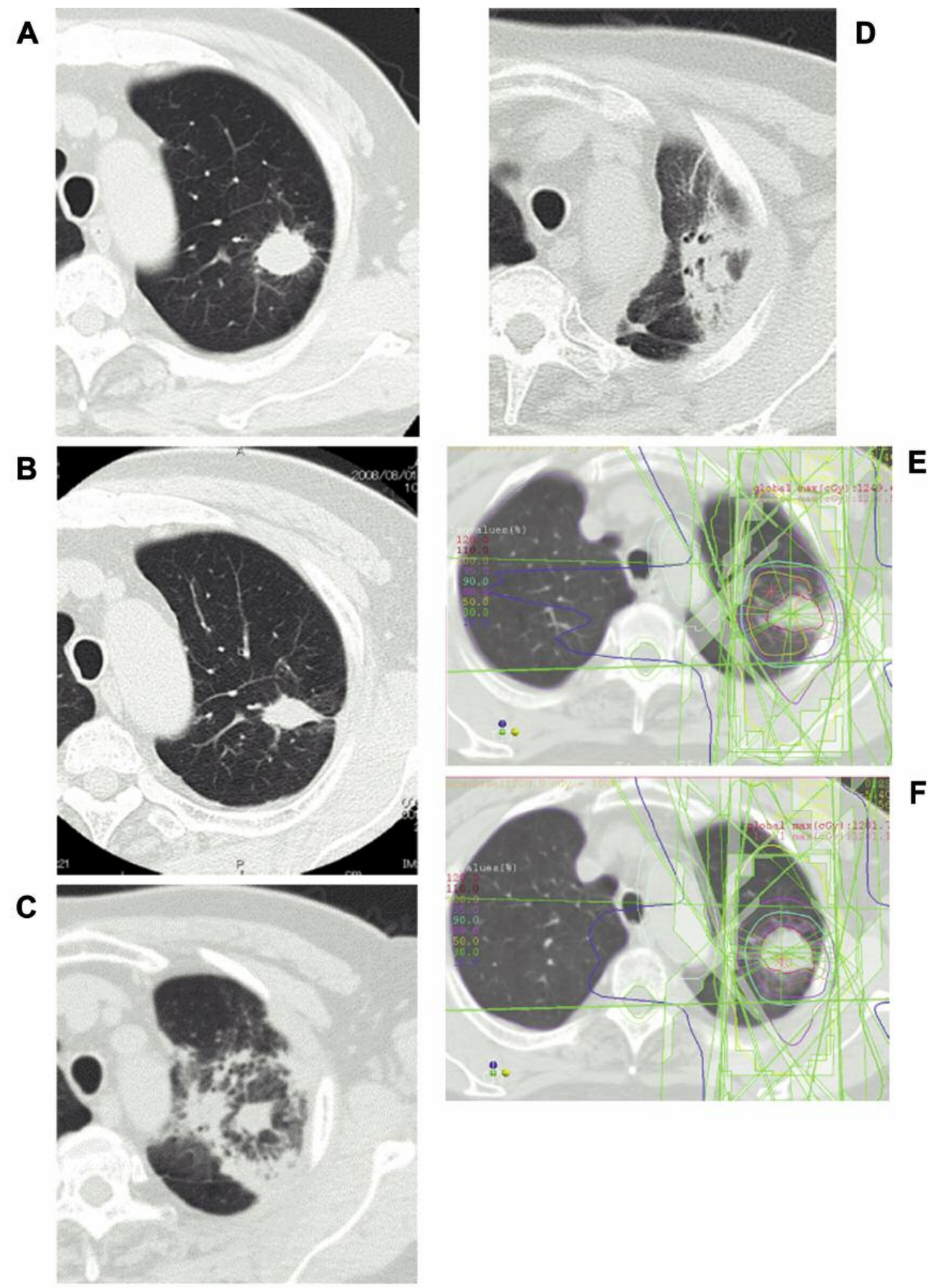

Figure 3. Computed tomographic images obtained before (A) and $4(B), 9(C)$ and 12 months $(D)$ after completion of stereotactic body radiotherapy (SBRT) for lung cancer in a 73-year-old man with non-small cell carcinoma in the left upper lobe. Cavity (sunny-side-up egg-like) changes after SBRT were seen at 9 months $(C)$. The time until disappearance of these cavity changes was 12 months (D). E and F: SBRT image with isodose lines. The blue line is the $90 \%$ isodose curve and corresponds to the planning target volume (PTV), as determined by the Clarkson method (E). The pink line is the $80 \%$ isodose curve and corresponds to the PTV obtained by employing the superposition technique $(F)$. 

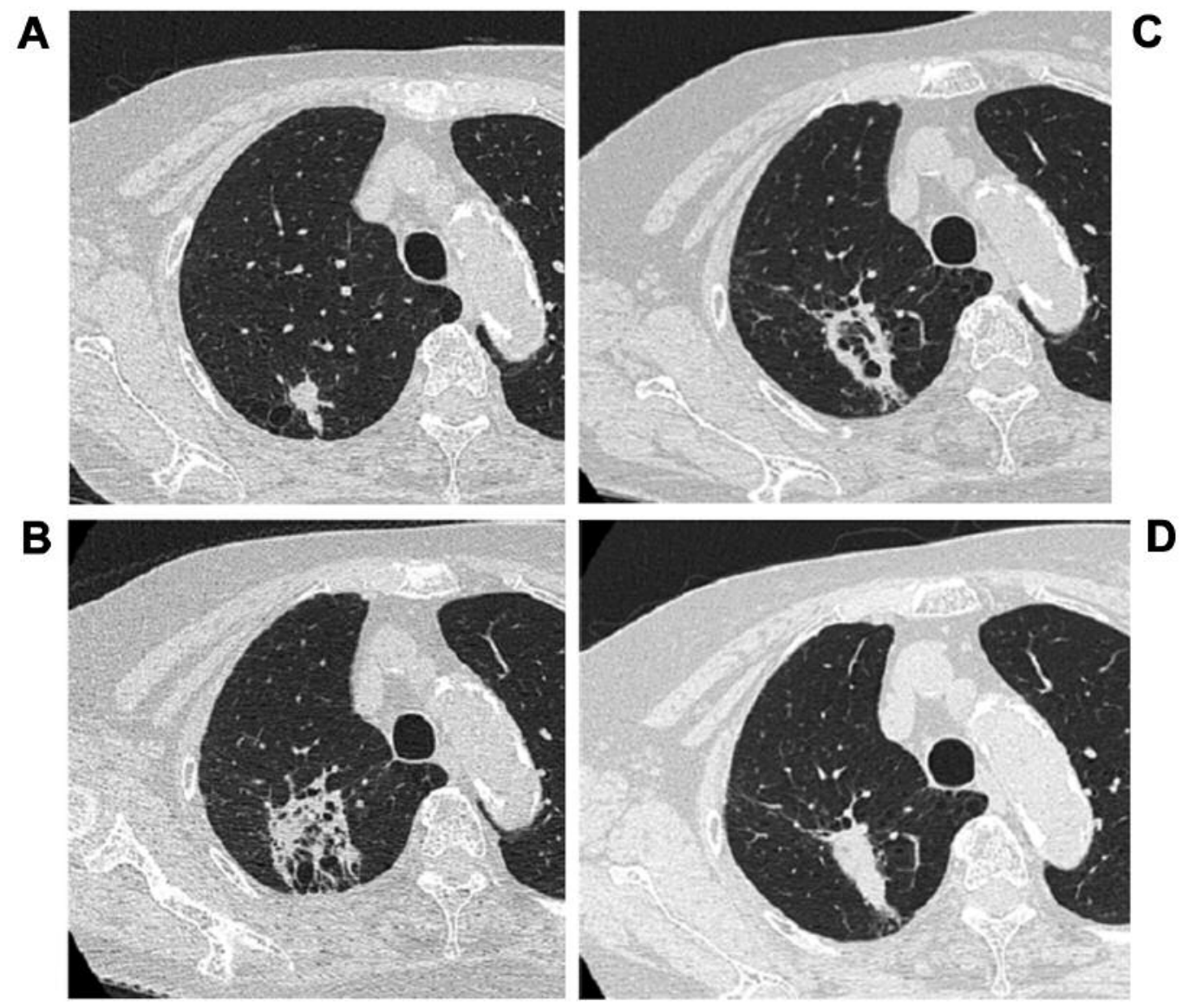

Figure 4. Computed tomographic images before (A) and $5(B), 12(C)$ and 20 months $(D)$ after completion of stereotactic body radiotherapy (SBRT) for suspicion of lung cancer in an 85-year-old woman with a nodule in the right upper lobe of the lung based solely on positron-emission tomography. Cavity (sunny-side-up egg-like) changes after SBRT were seen at 5 months $(B)$. The time until disappearance of these cavity changes was 20 months $(D)$.

Generally, radiation pneumonitis develops 3-4 months after irradiation, and radiation fibrosis has been recognized as late as 12 months. Aoki et al. (15) and Takeda et al. (6) reported radiation pneumonitis observed after SBRT to be similar in form to that seen after conventional radiotherapy. According to Koening et al., the incidence of mass-like fibrosis after conventional radiotherapy was $42 \%$ (17). Among the studies on solid or mass-like consolidation after SBRT, those by Takeda et al. (6), Aoki et al. (15), and Matsuo et al. (16) documented incidence rates of $78 \%, 65 \%$, and $68 \%$, respectively.

In view of the reported features of pneumonitis observed after conventional and stereotactic radiotherapy, we may infer that the development of pneumonitis after this form of treatment (considered to be a radical therapy for local tumor control) makes the diagnosis of residual lesions or tumor recurrence more difficult. The present results are consistent with our previous experience and past reports, suggesting a high likelihood of solid consolidation as a change detectable on diagnostic imaging after SBRT. As this consolidation forms, it becomes increasingly difficult for clinicians to judge whether the tumor has recurred.

Furthermore, during the present study, we detected cavitylike changes after SBRT, and found that judging whether such changes represent areas of solid consolidation or tumor recurrence was often difficult. We thus speculate that changes observed after high-dose irradiation have unique features (18). In cases with cavity changes, local recurrence or infection needs to be considered in making the differential diagnosis. Furthermore, Yoshida et al. advocated confined cavity formation inside a consolidated area as being one of the CT-based diagnostic criteria for local tumor recurrence after conventional radiotherapy. (19)

Choi et al. reported that scar-like changes observed in the lungs after high-dose stereotactic radiotherapy are difficult to distinguish from tumor recurrence (22), although neither 
these authors nor others have referred to cavity formation in this context. Two earlier reports support the view that cavity formation occurs via the check-valve mechanism involving treatment-induced interstitial necrosis and bronchial stenosis. $(20,21)$. We consider the cavity-like changes in our cases to probably represent traction changes due to the treatmentrelated check-valve mechanism.

Findings reported to date that suggest recurrence after SBRT include air bronchogram disappearance and the development of hydrothorax $(23,24)$, increase in size of the mass-like consolidation at 12 months (16), and regrowth (6). We experienced one local recurrence in a patient with metastatic lung cancer who underwent SBRT. Since local tumor recurrence after SBRT included the development of consolidation (16) and regrowth (6), findings were similar to those described in these past reports. In our four cases presenting with cavity changes, findings did not correspond to with those in past reports $(6,16,23,24)$. Studies have examined the possibility of tumor recurrence as assessed by PET, noting recurrence at 3-6 months after SBRT to be possible at a standardized uptake value of 5.0 or higher $(6,25)$. Although it is difficult to assess the surrounding lung in patients who have undergone SBRT with a small radiation field, when we studied CT images in detail, we found that the change was mainly outside of the CTV. In other words, our experience suggests that the central portion reflects the change in CTV. Hence, a PET scan may be particularly useful for detecting NSCLC recurrence after SBRT.

Because the lung changes observed after high-dose SBRT apparently differ from those after conventional radiotherapy, we will continue our follow-up of additional cases and carefully evaluate all data obtained.

\section{Conclusion}

SBRT is a viable treatment option for nonsurgical candidates with stage I NSCLC. Cavity (sunny-side-up egg-like) changes in the lungs may develop after SBRT for stage I NSCLC.

\section{Consent for Publication}

Written informed consent was obtained from the patients for publication of this article and any accompanying images.

\section{Conflicts of Interest}

The Authors have no conflicts of interest to declare.

\section{Acknowledgements}

The Authors thank Bierta Barfod for her contribution in revising the English language of this manuscript.

\section{References}

1 The Lung Cancer Management Guidelines 2014 (Japan Lung Cancer Society; https://www.haigan.gr.jp/modules/guideline/ index)

2 Nagata Y, Hiraoka M, Shibata T, Onishi H, Kokubo M, Karasawa K, Shioyama Y, Onimaru R, Kozuka T, Kunieda E, Saito T, Nakagawa K, Hareyama M, Takai Y, Hayakawa K, Mitsuhashi N and Ishikura S: Prospective trial of stereotactic body radiation therapy for both operable and inoperable T1N0M0 Non-Small Cell Lung Cancer: Japan Clinical Oncology Group Study JCOG0403. Int J Radiat Oncol Biol Phys 93: 989996, 2015.

3 Onishi H, Shirato H, Nagata Y, Hiraoka M, Fujino M, Gomi K, Niibe Y, Karasawa K, Hayakawa K, Takai Y, Kimura T, Takeda A, Ouchi A, Hareyama M, Kokubo M, Hara R, Itami J, Yamada $\mathrm{K}$ and Araki T: Hypofractionated stereotactic radiotherapy (HypoFXSRT) for stage I non-small cell lung cancer: updated results of 257 patients in a Japanese multi-institutional study. J Thorac Oncol 2: 94-100, 2007.

4 Timmerman R, Paulus R, Galvin J, Michalski J, Straube W, Bradley J, Fakiris A, Bezjak A, Videtic G, Johnstone D, Fowler $\mathrm{J}$, Gore $\mathrm{E}$ and Choy $\mathrm{H}$ : Stereotactic body radiation therapy for inoperable early stage lung cancer. JAMA 303: 1070-1076, 2010.

5 Chi A, Liao Z, Nguyen NP, Xu J, Stea B and Komaki R. Systemic review of the patterns of failure following stereotactic body radiation therapy in early-stage non-small-cell lung cancer: clinical implications. Radiother Oncol 94: 1-11, 2010.

6 Takeda A, Kunieda E, Takeda T, Tanaka M, Sanuki N, Fujii H, Shigematsu $\mathrm{N}$ and Kubo A. Possible misinterpretation of demarcated solid patterns of radiation fibrosis on CT scans as tumor recurrence in patients receiving hypofractionated stereotactic radiotherapy for lung cancer. Int J Radiat Oncol Biol Phys 70: 1057-1065, 2008.

7 Uematsu M, Shioda A, Suda A, Fukui T, Ozeki Y, Hama Y, Wong JR and Kusano S: Computed tomography-guided frameless stereotactic radiotherapy for stage I non-small cell lung cancer: a 5-year experience. Int J Radiat Oncol Biol Phys 51: 666-670, 2001.

8 Wulf J, Haedinger U, Oppitz U, Thiele W, Mueller G and Flentje M: Stereotactic radiotherapy for primary lung cancer and pulmonary metastases: a noninvasive treatment approach in medically inoperable patients. Int J Radiat Oncol Biol Phys 60: 186-196, 2004

9 Xia T, Li H, Sun Q, Wang Y, Fan N, Yu Y, Li P and Chang JY: Promising clinical outcome of stereotactic body radiation therapy for patients with inoperable Stage I/II non-small-cell lung cancer. Int J Radiat Oncol Biol Phys 66: 117-125, 2006.

10 Onimaru R, Shirato H, Shimizu S, Kitamura K, Xu B, Fukumoto S, Chang TC, Fujita K, Oita M, Miyasaka K, Nishimura M and Dosaka-Akita H: Tolerance of organs at risk in small-volume, hypofractionated, image-guided radiotherapy for primary and metastatic lung cancers. Int J Radiat Oncol Biol Phys 56: 126$135,2003$.

11 Timmerman R, Papiez L, McGarry R, Likes L, DesRosiers C, Frost $\mathrm{S}$ and Williams $\mathrm{M}$ : Extracranial stereotactic radioablation: results of a phase I study in medically inoperable stage I non-small cell lung cancer. Chest 124: 1946-1955, 2003. 
12 Nagata Y, Takayama K, Matsuo Y, Norihisa Y, Mizowaki T, Sakamoto T, Sakamoto M, Mitsumori M, Shibuya K, Araki N, Yano S and Hiraoka M: Clinical outcomes of a phase I/II study of $48 \mathrm{~Gy}$ of stereotactic body radiotherapy in 4 fractions for primary lung cancer using a stereotactic body frame. Int J Radiat Oncol Biol Phys 63: 1427-1431, 2005.

13 Xia T, Li H, Sun Q, Wang Y, Fan N, Yu Y, Li P and Chang JY: Promising clinical outcome of stereotactic body radiation therapy for patients with inoperable Stage I/II non-small-cell lung cancer. Int J Radiat Oncol Biol Phys 66: 117-125, 2006.

14 Baumann P, Nyman J, Hoyer M, Wennberg B, Gagliardi G, Lax I, Drugge N, Ekberg L, Friesland S, Johansson KA, Lund JA, Morhed E, Nilsson K, Levin N, Paludan M, Sederholm C, Traberg A, Wittgren L and Lewensohn R: Outcome in a prospective phase II trial of medically inoperable stage I nonsmall-cell lung cancer patients treated with stereotactic body radiotherapy. J Clin Oncol 27: 3290-3296, 2009.

15 Aoki T, Nagata Y, Negoro Y, Takayama K, Mizowaki T, Kokubo M, Oya N, Mitsumori M and Hiraoka M: Evaluation of lung injury after three-dimensional conformal stereotactic radiation therapy for solitary lung tumors: CT appearance. Radiology 230: 101-108, 2004.

16 Matsuo Y, Nagata Y, Mizowaki T, Takayama K, Sakamoto T, Sakamoto M, Norihisa Y and Hiraoka M: Evaluation of masslike consolidation after stereotactic body radiation therapy for lung tumors. Int J Clin Oncol 12: 356-362, 2007.

17 Koenig TR, Munden RF, Erasmus JJ, Sabloff BS, Gladish GW, Komaki R and Stevens CW: Radiation injury of the lung after three-dimensional conformal radiation therapy. AJR Am J Roentgenol 178: 1383-1388, 2002.

18 Pagani JJ and Libshitz HI: CT manifestations of radiationinduced change in chest tissue. J Comput Assist Tomogr 6: 243248,1982
19 Yoshida S, Maeda T, Yamamoto Y, Nishioka M, Sawada A, Kamiike O, Morita M, Hamada F, Inomata Y and Ohara S: Imaging of local recurrence of lung cancer after radiation therapy. [Article in Japanese] Rinsho Hoshasen 32: 51-57, 1987.

20 Bateson EM: So-called hamartoma of the lung - a true neoplasm of fibrous connective tissue of the bronchi. Cancer 31: 1458-67, 1973.

21 Quigley MJ and Fraser RS: Pulmonary pneumatocele: pathology and pathogenesis. AJR Am J Roentgenol 150: 1275-1277, 1988.

22 Choi YW, Munden RF, Erasmus JJ, Park KJ, Chung WK, Jeon SC and Park CK: Effects of radiation therapy on the lung: radiologic appearances and differential diagnosis. Radiographics 24: 985-997, 2004.

23 Huang K, Dahele M, Senan S, Guckenberger M, Rodrigues GB, Ward A, Boldt RG and Palma DA: Radiographic changes after lung stereotactic ablative radiotherapy (SABR) - can we distinguish recurrence from fibrosis? A systematic review of the literature. Radiother Oncol 102: 335-342, 2012.

24 Kato S, Nambu A, Onishi H, Saito A, Kuriyama K, Komiyama $\mathrm{T}$, Marino $\mathrm{K}$ and Araki T: Computed tomography appearances of local recurrence after stereotactic body radiation therapy for stage I non-small-cell lung carcinoma. Jpn J Radiol 28: 259-265, 2010.

25 Senthi S, Lagerwaard FJ, Haasbeek CJ, Slotman BJ and Senan S: Patterns of disease recurrence after stereotactic ablative radiotherapy for early stage non-small-cell lung cancer: a retrospective analysis. Lancet Oncol 13: 802-809, 2012.

Received July 5, 2016

Revised July 21, 2016

Accepted July 27, 2016 